\title{
Accessibility Metrics of Web Pages for Blind End-Users ${ }^{1}$
}

\author{
Julia González, Mercedes Macías, Roberto Rodríguez, and Fernando Sánchez \\ Escuela Politécnica. University of Extremadura \\ Avd. Universidad s/n, 10071, Cáceres, Spain \\ \{juliagon, mmaciasg, rre, fernando\}@unex.es
}

\begin{abstract}
The Internet offers new possibilities to the access of information, but sometimes the design of web pages obstructs the contents making them inaccessible to everybody, especially for those people with visual disabilities. Accessibility of web pages is an area that is gaining more and more interest. Not only do we have technique recommendations from the World Wide Web Consortium but also legal policies following these recommendations in several countries. In order to measure the fulfilment of these guidelines, different tools have been designed. These tools are useful mainly from the point of view of designers. However, they do not offer a global indicator of accessibility to endusers at the moment of surfing the net. For visually handicapped people, especially blind people, not only is a way necessary to know the degree of accessibility of web pages when being visited (not only the page as a whole, but also the different parts of the page). In the context of the project KAI (Kit for the Accessibility to the Internet), an accessibility measurement module has been developed, able to give a global indicator of accessibility at the moment of surfing the net. Moreover, the degree to which accessibility can be obtained in an independent way for each element belonging to the web page. This paper presents the main ideas behind this module.
\end{abstract}

\section{Introduction}

Since its creation the Internet has offered new branch of possibilities to the access of information. Through this media, published data are available in the entire world at the same time. But sometimes the design of pages and web applications are not accessible for everybody. People with disabilities often find difficulties when retrieving information from the net. Some interfaces have replaced the functionality and simplicity with aesthetics and attractiveness; this obstructs the access to the contents, especially for people whose physical disabilities make them unable to enjoy with the design, blind people.

Accessibility of web pages and applications has been recently considered. On the contrary to other fields, technical recommendations have been defined before legal policies. The most important recommendation has been made by the World Wide Web Consortium, W3C [1]. In 1995 the W3C formed a workgroup devoted to accessibility issues, called Web Accessibility Initiative, WAI [2]. Four years later, in 1999, the Web Content Accessibility Guidelines 1.0 [3] were published.

${ }^{1}$ This work has been developed with the support of CICYT under project TIC2002-04309-C02-

01 and Junta de Extremadura under project 2PR01A023 
On the other hand, some countries have recently established policies of accessibilities. The USA, in 2000, defined the standards of Section 508, Rehabilitation Act [4]. This norm establishes that all software products sold to Federal Agencies should accomplish this section. Paragraph 1194.22 is related to Web-based intranet and Internet information and applications and its points are based on the WAI guidelines. In Europe, the action plan eEurope 2005 [5] has been approved. This plan indicates that WAI guidelines must be taken into account, but they are not mandatory.

All the policies have taken WAI guidelines as a foundation, because these guidelines provide technical criteria to code a site in the right way, obtaining, according to accessibility, correct structure and functionality. In this document fourteen guidelines are defined, each one having different checkpoints classified into three categories, according to their relevance:

- Priority 1 , mandatory

- Priority 2, strongly desirable

- Priority 3, simply desirable

Different techniques of implementation have been defined and tools such as Bobby [6] or Taw [7] have been designed to validate the fulfillment of these guidelines. These tools analyze each element on a page verifying automatically many checkpoints and pointing out those checkpoints that should be verified by hand. As such, it is necessary to be an evaluator to know whether a page is accessible or not. These tools are useful for designers. But, what happens with end-users? How do they know the degree of accessibility of the web page being visited? How do they know the degree of accessibility of the different parts of the web page? How can a blind user decide if he or she must leave the web page because of its inaccessibility? To our knowledge there is no tool integrated in a web browser or search engine able to give a global indicator of web accessibility for blind users.

So, our position is that it is important for an end user to know clearly if a page is accessible or not. For a user with visual handicaps it is essential to know which pages are accessible in order to choose the most suitable for his/her needs. Not always is the page with more accurate information about the searched topic, the best for him/her. It is surely better to recover a page less accurate but more accessible.

In this paper we present a module for web accessibility measurement. This module has been integrated in KAI, a Kit for the Accessibility to the Internet for blind people. In section 2, an overview of KAI is shown; section 3 presents the different metrics to measure accessibility and, finally, section 4 shows conclusions and future work.

\section{Overview of KAI}

KAI [8] tries to make navigation easier for blind people. It relies on two different parts: software and hardware components. Its software component is based on BML (Blind Markup Language) a new language developed following the specifications of XML. This language has been designed to build accessible web pages. One can write code directly in BML or one can translate existing HTML code to BML. In this second case, the page is filtered, repaired, and restructured according to the user needs. Once the page has been improved it can be shown in whatever browser (translating the page again into HTML) or it can be shown in WebTouch [9], which is the hard- 
ware component of KAI. WebTouch is a multimodal web browser. It gives the user the possibility to access the information using tactile or/and auditory skills. The input devices are the keyboard, the mouse and a voice recognition system [10]. The output devices are a special mouse (PinMouse), a synthesizer and the screen (for visually unimpaired users).

Taking into account the problems of visually handicapped people, WebTouch offers the possibility of configuring the mode of navigation: visually, by audio, by touch or a combination of them. One of the main advantages of WebTouch is selective reading rather than sequential. For example, one can choose surfing only by way of e-mail addresses. In this way, finding information for blind users is quicker.

Figure 1.a shows an example of a web page in a usual web browser, and in Figure 1.b the same page is shown in WebTouch. All the elements shown on the page, figure 1.b, are icons. There is a special mouse also developed in the context of KAI, PinMouse, with two cells of pins. When the mouse is over an icon the pins raise in such a way that the user can know the kind of element below the mouse. The pins also give information about the accessibility of the element. For example, if the element below the mouse is a table, one can obtain information such as if the table has a summary or a title or appropriate headers.

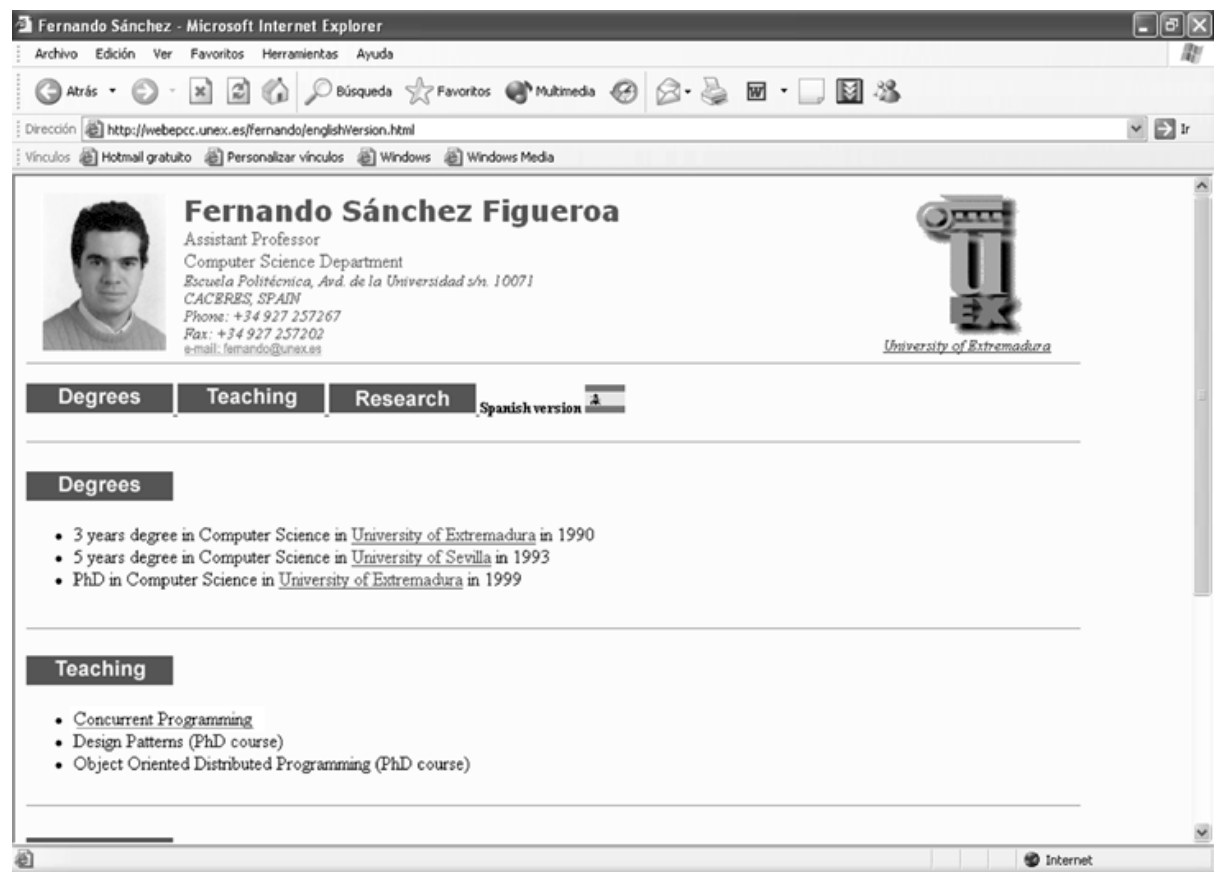

Fig. 1.a. Web page in a usual Web Browser

When the link of a page has been written, and before it is presented, its accessibility is calculated, giving the user the possibility to reject it according to a single value expressed as a percentage. In this process an accessibility data structure of the original web page is obtained. Once the page has been translated into BML, the same process 
is carried out, getting an accessibility data structure for BML. This structure stores the accessibility information of each BML element.

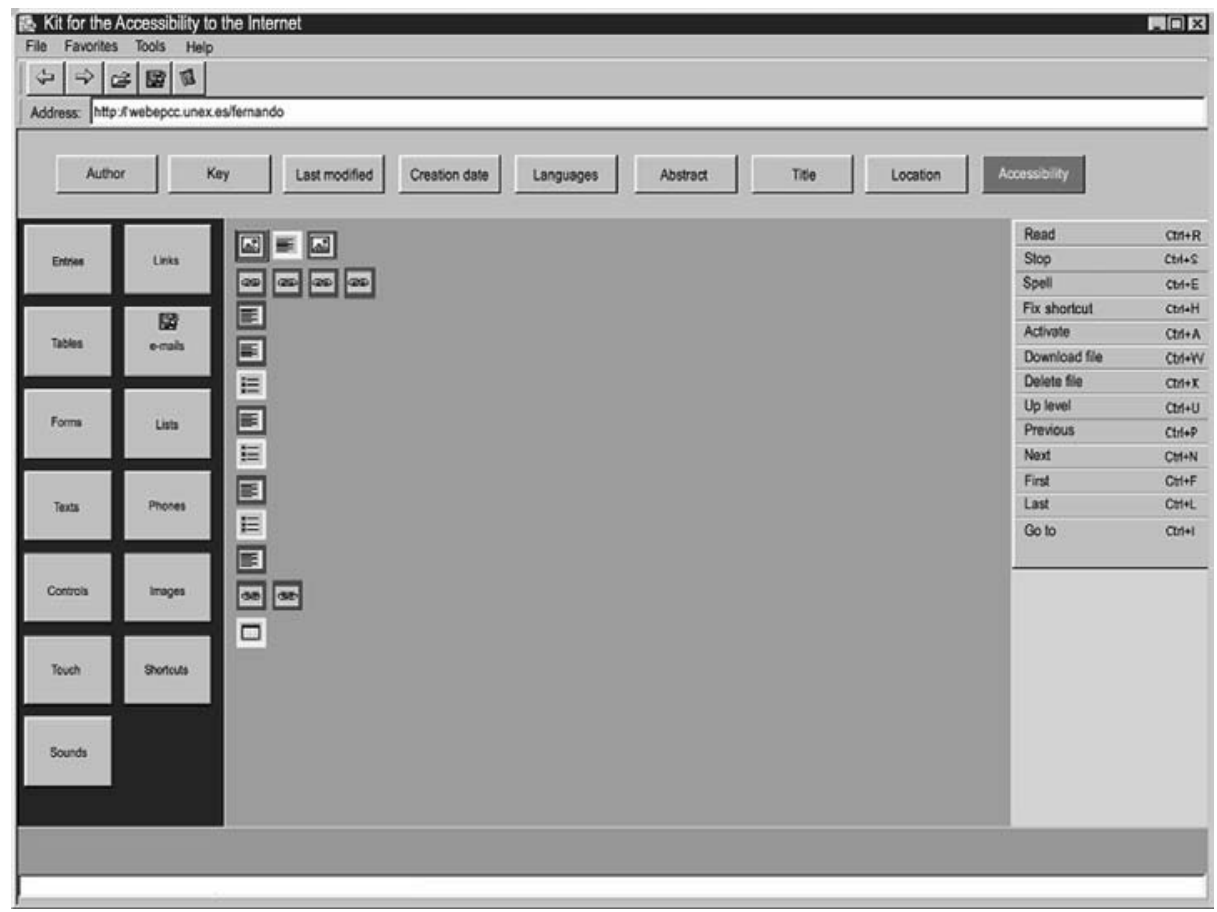

Fig. 1. b. A graphic representation of the previous web page in WebTouch

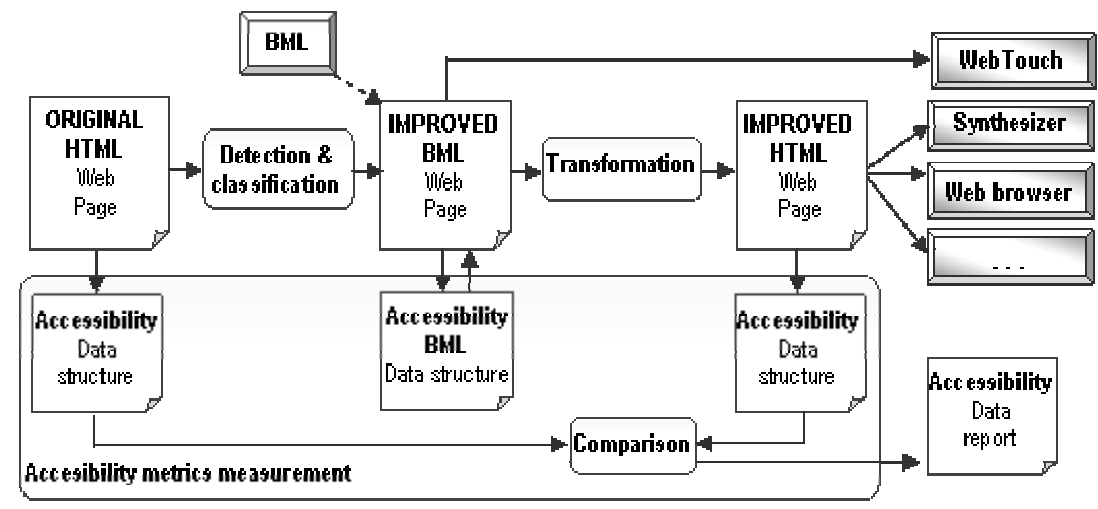

Fig. 2. Architecture of KAI 
At the end both values, original and improved pages, can be compared in order to ascertain the achievements of KAI.

All the steps are shown in Figure 2. Although the accessibility module also pretends to measure the satisfaction of the user with different output systems, and establishes the profits of our platform WebTouch, quality in use is not considered in this work. In this paper we just present the way of measuring the accessibility in KAI.

\section{Measuring Accessibility in KAI}

Our goal is to obtain a global accessibility indicator, and to add this functionality to our platform, although the process could be added to any system. It is also interesting to know the global quality of the page that has been modeled in ISO 9126 [11], ISO 14598-5 [12] and IEEE 1061 [13] as a main characteristic formed by a minimum set of characteristics and "these characteristics should be hierarchically decomposed into a quality model composed of characteristics and sub characteristics which can be used as a checklist of issues related to quality" (ISO/IEC 9126 [11]).

The standards do not elaborate the model under the level of sub characteristics, so the evaluator establishes the attributes that should be measured according to the need of the evaluation using an integral methodology. In [14] a methodology has been defined covering the main activities of a software life cycle. Starting from the six main characteristics of ISO9126, it presents a set of sub characteristics and attributes to measure the quality and to obtain a global indicator for the overall quality of the considered product, specifically a web artifact.

We can consider accessibility as a sub characteristic of functionality, which directly affect overall quality. Metrics for the other characteristics have been developed in some previous papers [15]. We have centered on the metrics of accessibility according to WAI guidelines and the elements of a page, and the opinion of blind people who have been working with us during the last year.

We have identified the following elements: text, list, link, image, sound, multimedia element, executable element, table and form on a page. These elements have also been considered in BML, but some of them with a different implementation: text, (could be heading, paragraph, cite or code), list, link (internal, web, archive and software), image, sound, table and form.

In the process of translating into BML, a data structure is generated. This structure is generated in the analysis and stores data about all the elements on each page. The evaluation is helped by this structure and improved pages can be studied while they are coded in BML. We have built a table that has an entry for each element on a page, and we have established the checkpoints of the WAI guidelines related to the element. As the guidelines are not measurable by themselves, a set of metrics is grouped for each checkpoint.

The structure of the table offers the defined set of metrics for each previously considered element. In the first column, the element is defined; the criteria used to check it is in the second, usually WAI guidelines and their priorities, the relative importance given by a visually handicapped person to that guideline is in the following and the metrics related to the checkpoint is in the last one. 
Table 1. Metrics for WAI guidelines

\begin{tabular}{|c|c|c|c|c|c|}
\hline & \multicolumn{3}{|r|}{ Criteria } & \multirow{2}{*}{$\begin{array}{l}\text { Relative im- } \\
\text { portance }\end{array}$} & \multirow{2}{*}{ Metrics } \\
\hline & \multicolumn{2}{|c|}{ WAI } & Checkpoint & & \\
\hline \multirow{9}{*}{ 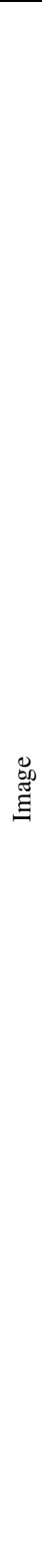 } & \multirow[t]{4}{*}{ : } & 1.1 & $\begin{array}{l}\text { Provide a text equivalent for } \\
\text { every non-text element }\end{array}$ & $100 \%$ & $\begin{array}{l}\% \text { different visual information } \\
\% \text { images with descriptive/non } \\
\text { descriptive alternative text } \\
\% \text { images with long descriptive/non } \\
\text { descriptive description } \\
\% \text { different images with descrip- } \\
\text { tive/non descriptive alternative text } \\
\% \text { different images with long descrip- } \\
\text { tive/non descriptive description } \\
\% \text { images with descriptive/non } \\
\text { descriptive alternative text or long de- } \\
\text { scription } \\
\% \text { different images with descrip- } \\
\text { tive/non descriptive alternative text or } \\
\text { long description } \\
\% \text { descriptive alternative texts } \\
\% \text { descriptive long descriptions }\end{array}$ \\
\hline & & 2.1 & $\begin{array}{l}\text { Ensure that all information con- } \\
\text { veyed with color is also avail- } \\
\text { able without color, for example } \\
\text { from context or markup }\end{array}$ & $100 \%$ & $\begin{array}{l}\% \text { images seen without colour } \\
\% \text { different images seen without colour } \\
\% \text { images with high contrast }\end{array}$ \\
\hline & & 1.2 & $\begin{array}{l}\text { Provide redundant text links for } \\
\text { each active region of a server- } \\
\text { side image map }\end{array}$ & $100 \%$ & $\begin{array}{l}\mathrm{N}^{\circ} \text { maps } \\
\text { Average zones/map } \\
\% \text { zones with links } \\
\% \text { average of zones with links per map }\end{array}$ \\
\hline & & 9.1 & $\begin{array}{l}\text { Provide client-side image maps } \\
\text { instead of server-side image } \\
\text { maps except where the regions } \\
\text { cannot be defined with an avail- } \\
\text { able geometric shape }\end{array}$ & \%blindness & 1.2 \\
\hline & \multirow[t]{2}{*}{ 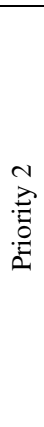 } & 2.2 & $\begin{array}{l}\text { Ensure that foreground and } \\
\text { background color combinations } \\
\text { provide sufficient contrast when } \\
\text { viewed by someone having } \\
\text { color deficits or when viewed } \\
\text { on a black and white screen. }\end{array}$ & $\begin{array}{l}\% \\
\text { (1/blindness) }\end{array}$ & $\begin{array}{l}\mathrm{N}^{o} \text { changes in background colour } \\
\mathrm{N}^{o} \text { changes in foreground colour } \\
\mathrm{N}^{o} \text { colours used as background } \\
\mathrm{N}^{o} \text { colours used as foreground } \\
\mathrm{N}^{o} \text { different matches back- } \\
\text { ground/foreground } \\
\mathrm{N}^{\circ} \text { matches with high contrast } \\
\% \text { matches with high contrast } \\
\text { The most used background colour } \\
\text { The most used foreground colour }\end{array}$ \\
\hline & & 3.1 & $\begin{array}{l}\text { When an appropriate mark-up } \\
\text { language exists, use mark-up } \\
\text { rather than images to convey in- } \\
\text { formation }\end{array}$ & \%blindness & $\begin{array}{l}\text { \% images used as marks } \\
\% \text { different images used as marks } \\
\mathrm{N}^{\mathrm{o}} \text { equivalent marks } \\
\% \text { images with equivalent mark }\end{array}$ \\
\hline & 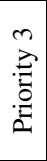 & 1.5 . & $\begin{array}{l}\text { Until user agents render text } \\
\text { equivalents for client-side image } \\
\text { map links, provide redundant } \\
\text { text links for each active region } \\
\text { of a client-side image map }\end{array}$ & & 1.2 and 9.1 \\
\hline & \multicolumn{5}{|c|}{ Others } \\
\hline & & & $\begin{array}{l}\text { Images used to supply textual } \\
\text { information }\end{array}$ & \%blindness & $\%$ images containing text \\
\hline
\end{tabular}




\begin{tabular}{|c|c|c|c|c|c|}
\hline & \multicolumn{3}{|c|}{$\begin{array}{r}\text { Criteria } \\
\end{array}$} & \multirow{2}{*}{$\begin{array}{l}\text { Relative im- } \\
\text { portance }\end{array}$} & \multirow{2}{*}{ Metrics } \\
\hline & & AI & Checkpoint & & \\
\hline \multirow{7}{*}{$\frac{0}{\frac{0}{0}}$} & \multirow[t]{3}{*}{ : } & 1.1 & $\begin{array}{l}\text { Provide a text equivalent for } \\
\text { every non-text element }\end{array}$ & \%blindness & $\begin{array}{l}\% \text { tables with descriptive/non descrip- } \\
\text { tive alternative text } \\
\% \text { tables with long descriptive/non de- } \\
\text { scriptive description } \\
\% \text { different tables with descriptive/non } \\
\text { descriptive alternative text } \\
\% \text { different tables with long descrip- } \\
\text { tive/non descriptive description } \\
\% \text { tables with descriptive/non descrip- } \\
\text { tive alternative text or long description } \\
\% \text { different tables with descriptive/non } \\
\text { descriptive alternative text or long de- } \\
\text { scription } \\
\% \text { descriptive alternative texts } \\
\% \text { descriptive long descriptions } \\
\end{array}$ \\
\hline & & 5.1 & $\begin{array}{l}\text { For data tables, identify row and } \\
\text { column headers }\end{array}$ & \%blindness & $\begin{array}{l}\text { \%tables with identified rows } \\
\text { \%tables with identified headers } \\
\% \text { tables with identified rows and iden- } \\
\text { tified headers }\end{array}$ \\
\hline & & 5.2 & $\begin{array}{l}\text { For data tables that have two or } \\
\text { more logical levels of row or } \\
\text { column headers, use markup to } \\
\text { associate data cells and header } \\
\text { cells }\end{array}$ & \%blindness & $\begin{array}{l}\text { Maximum logical level } \\
\text { Minimum logical level } \\
\text { \%tables with more than one level }\end{array}$ \\
\hline & \multirow[t]{2}{*}{$\stackrel{\substack{0 \\
D}}{2}$} & 5.3 & $\begin{array}{l}\text { Do not use tables for layout } \\
\text { unless the table makes sense } \\
\text { when linearized. Otherwise, if } \\
\text { the table does not make sense, } \\
\text { provide an alternative equiva- } \\
\text { lent }\end{array}$ & \%blindness & $\begin{array}{l}\text { \%tables used for layout } \\
\text { \%layout tables with an linear equiva- } \\
\text { lent } \\
\mathrm{N}^{\circ} \text { different contended elements in a } \\
\text { table } \\
\text { \%cells containing images } \\
\text { \%cells containing links } \\
\text { \%cells containing tables } \\
\text { \%cells containing text } \\
\text { \%cells containing multimedia element } \\
\text { \%cells containing executable code }\end{array}$ \\
\hline & & $\begin{array}{l}5 . \\
4\end{array}$ & $\begin{array}{l}\text { If a table is used for layout, do } \\
\text { not use any structural markup } \\
\text { for the purpose of visual format- } \\
\text { ting }\end{array}$ & \%blindness & $\begin{array}{l}\text { \%false row marks } \\
\% \text { false header marks }\end{array}$ \\
\hline & \multirow{2}{*}{ 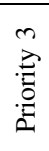 } & 5.5 & Provide summaries for tables & \%blindness & $\begin{array}{l}\text { \%tables with summaries } \\
\text { \%tables with descriptive summaries }\end{array}$ \\
\hline & & 5.6 & $\begin{array}{l}\text { Provide abbreviations for } \\
\text { header labels }\end{array}$ & \%blindness & \%headers with abbreviation \\
\hline & & & $\begin{array}{l}\text { If, after best efforts, you cannot } \\
\text { create an accessible page, pro- } \\
\text { vide a link to an alternative page } \\
\text { that uses W3C technologies, is } \\
\text { accessible, has equivalent in- } \\
\text { formation (or functionality), and } \\
\text { is updated as often as the inac- } \\
\text { cessible (original) page }\end{array}$ & \%blindness & \%alternative links \\
\hline
\end{tabular}

Some criteria do not match any guideline, and they are considered as other. Table 1 shows the entries for image and tables, the guidelines related to them and the metrics considered for each one. Other elements are left out for simplicity.

Images are one of the main reasons because a page is often inaccessible. For example, sometimes images are only used to represent text, avoiding the reading by a synthesizer, and, therefore, making this information inaccessible. The more visually 
impaired the person is, the more important the criterion is. However, the contrast of images is not useful for a person unable to distinguish it. Then, when the percentage of blindness increases, the importance of this guideline decreases for the user. Equally there are some guidelines that could be considered irrelevant for blind users.

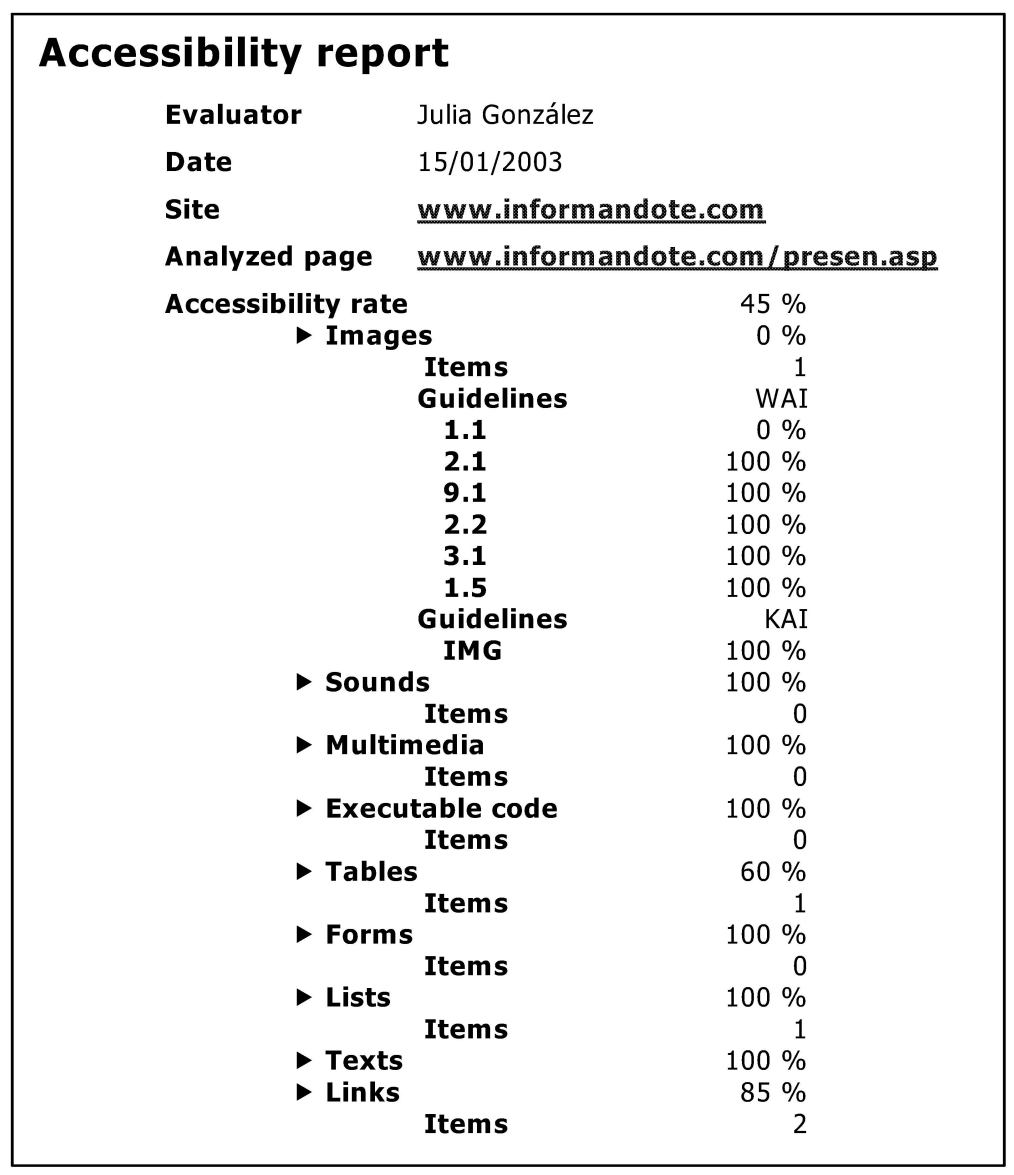

Fig. 3. Example of an accessibility report

Each element is considered individually and can be contended in other, e.g. a table might be accessible, but if an inaccessible image is in it, this will affect the table's accessibility rate. In Figure 3, an example of accessibility report is shown. The user can obtain this report before surfing the page. A blind user can access the report via a synthesizer. The example in the figure is an inaccessible page, because of the structure. The single image on the page does not have an alternative text, so visual information is lost. As there are not any sounds, forms, multimedia elements, or executable code, they are not used in the calculation. One table is used for layout, and also its headers, used to give format to the text. In spite of the table, the text is completely accessible and linear, therefore the table is quite accessible. With all this information the enduser decides whether to navigate through the page or not. 
Once that all the elements have been measured and we have obtained the accessibility reports, similar to Figure 3, for original and improved pages, they are compared in order to know the process achievements. If the accessibility rate obtained for the improved page is higher than the one obtained for the original one, KAI transformation would have improved the page, offering more accessibility to the end-user. The results obtained until now with simple pages written in HTML are reasonably good.

\section{Conclusions and Future Work}

With the Internet, barriers such us distance and technology have disappeared in the attempt to access to the information. But not all the barriers have been broken and even new ones have been built. A lot of sites are designed following principles of beauty and attractiveness instead of simplicity and functionality. These characteristics often entail a restrictive, insufficient and inadequate access to the information, especially for users with visual handicaps, such as blind people.

Accessibility has been recently considered, but it is a global goal, supported by technical recommendations, and legal policies. Considering these recommendations we have developed KAI. The aim of this tool is to provide more accessible information to blind users. KAI translates existed web pages into improved ones, more accessible, and also allows navigating through the page with WebTouch, a multimodal web browser, which allows the user to move around the page using his/her voice/audio/tactile skills. This platform also permits the end-user to know the accessibility rate of a web page, before being presented in WebTouch. For this, we consider WAI recommendations and data supplied by blind users.

The accessibility rate is calculated considering that a page is accessible if all of its elements are accessible. Giving the address of a web page it is established the accessibility rate of each element, and a general value for the page is calculated, following WebQEM [14].

The obtained rates of each page can be compared. We are interested in the comparison between an existing web page and its transformed page, in order to know KAI achievements.

The accessibility measurement module is still in progress and more functionality will be included. One of our goals is to know and quantify user satisfaction. Therefore new metrics and process are being designed to achieve this.

\section{References}

1. World Wide Web Consortium . http://www.w3c.org.

2. Web Accessibility Initiative. W3C. http://www.w3c.org/WAI.

3. Chisholm W., Vanderheiden G. and Jacobs I., "Web Content Accessibility Guidelines 1.0.", W3C Recommendation, http://www.w3.org/TR/WAI_WEBCONTENT/, 5/5/1999.

4. "Section 508 Rehabilitation Act". USA. http://www.section508.gov/final_text.html

5. "eEurope 2005. An information society for all". 28 May 2002. http://europa.eu.int/information_society/eeurope/news_library/eeurope2005/index_en.htm

6. "Bobby". Center for Applied Special Technology. http://www.cast.org/bobby

7. "TAW". Fondo Formación Asturias. http://www.tawdis.net 
8. Macías M., González-Rodríguez J., Sánchez F. ,’On Adaptability of Web Sites for Visually Handicapped People". In Adaptive Hypermedia and Adaptive Web-Based Systems. Ed. Springer-Verlag, LNCS 2347, Málaga, Spain, 2002.

9. Macías M., Sánchez F. "Improving Web Accesibility for visually Handicapped People Using KAI". $3^{\text {rd }}$ International Workshop on Web Site Evolution. IEEE Computer Society. ISBN: 0-7695-1399-9

10. Díaz, J.C.; García, J.J.; Álvarez, J.F.; Espada, P.; Gómez, P.; Rodríguez, J.M., ”DIARCA: A Component Approach to Voice Recognition". Eurospeech 2001, $7^{\text {th }}$ European Conference on Speech Communication and Technology, Aalborg, Denmark, 2001.

11. ISO/IEC 9126-1: 2001 (E), International Standard Software Engineering - Product Quality- Part 1: Quality model.

12. ISO/IEC 14598-5:1998 International Standard, Information technology - Software product evaluation - Part 5: Process for evaluators.

13. IEEE Std 1061-1992, IEEE Standard for a Software Quality Metrics Methodology.

14. Olsina L., "Web Engineering: A Quantitative Methodology for Quality Evaluation and Comparison of Web Applications". Doctoral Thesis (in Spanish), Ciencias Exactas School, UNLP, La Plata, Argentina, 2000.

15. Olsina L., González-Rodríguez, J., Lafuente G., Pastor O.; 2002, "Providing automated support to web metrics". $8^{\text {th }}$ Quality European Week, Brussels, Belgium, 2002 